\title{
Synergistic Antimicrobial Effect of Lonicera japonica and Magnolia obovata Extracts and Potential as a Plant-Derived Natural Preservative
}

\author{
Ye Seul Lee, Yun Ju Lee, and Soo Nam Park* \\ Department of Fine Chemistry, Cosmetic RED Center, Cosmetic Industry Coupled Collaboration Center, Seoul National University of \\ Science and Technology, Seoul 01811, Republic of Korea
}

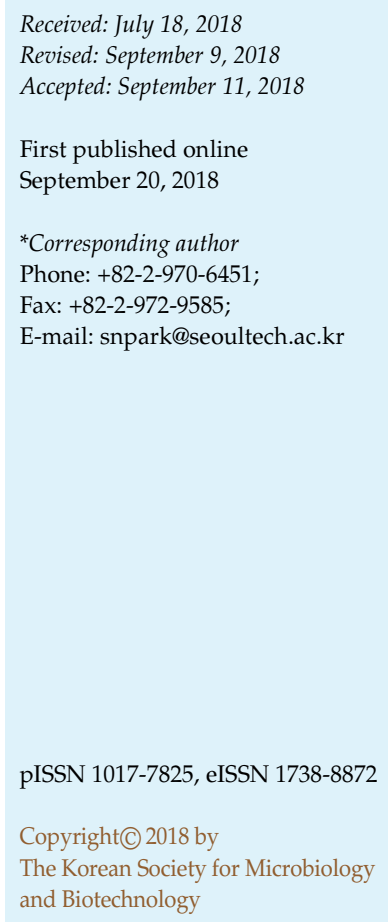

\begin{abstract}
Most people use cosmetics to protect their skin. Preservatives are often used to prevent their contamination upon use. There has been a great demand for natural preservatives due to recent reports on the side effects of parabens. Therefore, we evaluated the antimicrobial activities of Lonicera japonica and Magnolia obovata extracts and determined their potential as natural preservatives. We found that the $50 \%$ ethanol extract from L. japonica had antibacterial activity only against $S$. aureus and $P$. aeruginosa, while the ethyl acetate fraction showed antimicrobial activity against all six microbial strains tested. On the other hand, the $70 \%$ ethanol extract and the ethyl acetate fraction from M. obovata showed antimicrobial activity against all six strains. A synergistic effect against $S$. aureus, B. subtilis, and C. albicans was confirmed when two ethyl acetate fractions having antimicrobial activity against all six strains were used in combination. Synergistic activity against B. subtilis was also confirmed through kill-time analysis. Highperformance liquid chromatography was performed to identify the components of each extract. Based on the minimum inhibitory concentration and the results of a disc diffusion assay, we confirmed that caffeic acid and luteolin influenced the antimicrobial activity of L. japonica and that the antimicrobial activity of M. obovata was influenced by the interaction of magnolol and honokiol with other components. Therefore, this study suggests that the combination of L. japonica and M. obovata extracts may be used as a plant-derived natural preservative.
\end{abstract}

Keywords: Lonicera japonica, Magnolia obovata, antimicrobial activity, synergistic effect

\section{Introduction}

The skin is the outermost barrier of the human body. It plays a role in protecting the body from external stimuli such as ultraviolet rays, antigens, microorganisms, and chemical substances [1]. The skin preserves the body in various ways by controlling the $\mathrm{pH}$ on its surface, moisture content, and through secretion by the sebaceous glands and sweating. If the function of the skin barrier is compromised, pathogens can penetrate the skin and cause many skin diseases [2]. Therefore, people use cosmetics to maintain skin homeostasis and general skin health [3]. As interest in cosmetics has increased, the demand for these products has also grown rapidly. This eventually led to the development of plant-derived and eco-friendly products [4].
According to the United States Federal Food, Drug, and Cosmetic Act, cosmetics are defined as "articles intended to be rubbed, poured, sprinkled, or sprayed on, introduced into, or otherwise applied to the human body...for cleansing, beautifying, promoting attractiveness, or altering the appearance." Cosmetics contain large amounts of water, which could allow the survival of microorganisms and subsequently cause harmful skin diseases, even though their intended use is for skin protection [5]. Therefore, preservatives are added to cosmetics to prevent microbial contamination [6]. However, recent studies have reported that preservatives, especially parabens, may have side effects. Consequently, the demand for plant-derived natural cosmetics has increased, thereby spurring developments in studies on plant-derived preservatives $[7,8]$.

Lonicera japonica is a semi-evergreen, broad-leaved shrub 
that grows in mountains all over Korea. In Chinese medicine, it is known as "geum-eun-hwa". The stem, flower, and fruit of L. japonica have been used for medicinal purposes, for instance, in treating high fever, acute hepatitis, and inflammation. However, eating any part of the plant for a long time is discouraged because it is slightly toxic. Studies on the antioxidant, antibacterial, and anti-inflammatory properties of L. japonica extracts have been reported [9-12]. Magnolia obovata is a magnolia and a deciduous tree of Japanese and Chinese origin. It is often called magnolia or yellow magnolia. The bark of $M$. obovata is widely used to improve digestion, as a diuretic, and to control vomiting. The bark is used in Chinese medicine as an antioxidant, antibacterial, anti-inflammatory, and antidepressant [1316].

In this study, we evaluated the antimicrobial activities of L. japonica and M. obovata extracts against microorganisms regulated in cosmetics according to the Personal Care Products Council Microbiology Guidelines. The six regulated microorganisms used in this study were Staphylococcus aureus, Bacillus subtilis, Escherichia coli, Pseudomonas aeruginosa, Candida albicans, and Aspergillus brasiliensis. We also determined whether the antimicrobial properties of the two extracts could act synergistically. We used the ethyl acetate fractions that exhibited antimicrobial activity against all six strains. The components of each extract were identified through high-performance liquid chromatography (HPLC). In addition, the presence of the active components in each extract was confirmed by evaluating the antimicrobial activity of each component. This study provides insight into the applicability of L. japonica and M. obovata extracts as natural preservatives.

\section{Materials and Methods}

\section{Equipment and Reagents}

The UV-visible spectrophotometer used for experiments was a Cary 50 from Varian (Australia). Various solvents such as ethanol, methanol, and ethyl acetate were purchased from Daejung Chemicals \& Metals Co. (Korea). The caffeic acid and luteolin used as standards for comparison were purchased from Sigma Chemical Co. (USA). Magnolol and honokiol were purchased from ActivON. L. japonica and M. obovata were purchased from Gyeongdong market in Seoul, 2017.

\section{Extraction and Fractionation}

Four hundred grams of dried L. japonica was finely pulverized, immersed in $8 \mathrm{~L}$ of $50 \%$ ethanol for $24 \mathrm{~h}$, and then filtered. The filtrate was dried under reduced pressure to obtain a powder. The $50 \%$ ethanol extract was then fractionated three times with ethyl acetate, and the ethyl acetate fraction was concentrated to obtain a powder.

Three hundred grams of dried M. obovata was finely pulverized, stirred in $3 \mathrm{~L}$ of $70 \%$ ethanol for $24 \mathrm{~h}$ at $30{ }^{\circ} \mathrm{C}$, and then filtered. The filtrate was dried under reduced pressure to obtain a powder. Then, the $70 \%$ ethanol extract was fractionated three times with ethyl acetate, and the ethyl acetate fraction was concentrated to obtain a powder.

\section{Microbial Strains and Culture Conditions}

The strains used to evaluate the antimicrobial effect of the extracts were S. aureus ATCC 6538, B. subtilis ATCC 6051, E. coli ATCC 8739, P. aeruginosa ATCC 9027, C. albicans ATCC 10231, and A. brasiliensis ATCC 16404 obtained from the Korea Culture Center of Microorganisms (KCCM, Seoul, Korea). S. aureus, B. subtilis, E. coli, P. aeruginosa, and C. albicans were cultured on Tryptic Soy Agar (Merck, Germany) for $24 \mathrm{~h}$ at $37^{\circ} \mathrm{C}$ after inoculation. A. brasiliensis was inoculated onto Potato Dextrose Agar (Merck, Germany) and cultured in a $30^{\circ} \mathrm{C}$ incubator for $48 \mathrm{~h}$.

\section{Evaluation of Antimicrobial Activity}

Minimum inhibitory concentration (MIC) and minimum bactericidal concentration (MBC). To determine the minimum inhibitory concentration and the minimum bactericidal concentration for each extract, each strain was used at 3 to $5 \times 10^{6}$ colonyforming units (CFU)/ml. Methylparaben was used as a control. The samples were diluted with DMSO using a 2-fold dilution method [17]. Then, $20 \mu \mathrm{l}$ of the extract, $20 \mu \mathrm{l}$ of the microbial suspension (inocula), and $160 \mu \mathrm{l}$ of the medium (bacteria and yeast - Tryptic Soy Broth, mold - Potato Dextrose Broth) were added to the wells on a 96-well plate. The cells were then observed with the naked eye after cultivation (Bacteria and yeast were incubated for $18 \mathrm{~h}$ at $37^{\circ} \mathrm{C}$ and mold was incubated for $48 \mathrm{~h}$ at $30^{\circ} \mathrm{C}$.), and the concentration at which the microorganisms did not proliferate was determined to be the minimum inhibitory concentration. The concentration at which colonies were not formed upon inoculation of the culture on an agar plate with a sterilized cotton swab was determined to be the minimum bactericidal concentration.

Disc diffusion assay. The antimicrobial activity of each extract and each fraction obtained with different extraction conditions were determined through a disc diffusion assay. The cultured strains were used at $3 \sim 5 \times 10^{6} \mathrm{CFU} / \mathrm{ml}$. Then, $100 \mu \mathrm{l}$ of each strain was plated using a sterile spreader. Solutions containing $0.05 \mathrm{mg}$ (luteolin) or $5 \mathrm{mg}$ of the samples were absorbed slowly by paper discs (diameter: $8 \mathrm{~mm}$, Toyo Roshi Kaisha Ltd., Japan). The discs were then dried to volatilize the solvent and then incubated with the previously inoculated plates. The clear zone $(\mathrm{mm})$ formed around each disc was measured to compare the antimicrobial activities of the extracts.

\section{Synergistic Antimicrobial Effects of the Extracts}

Checkerboard test. The synergistic effect is generally determined 
Table 1. HPLC conditions for separation of EtOAc fraction from L. japonica.

\begin{tabular}{|c|c|c|c|c|}
\hline & \multicolumn{4}{|c|}{ Conditions of HPLC analysis } \\
\hline Column & \multicolumn{4}{|c|}{ Shim-pack VP-ODS C18 Column (L : $250 \mathrm{~mm}, \mathrm{LD}: 4.6 \mathrm{~mm}, 5 \mu \mathrm{m})$} \\
\hline Detector & \multicolumn{4}{|c|}{ UVD 170s DIONEX } \\
\hline Detection wavelength & \multicolumn{4}{|c|}{$254-400 \mathrm{~nm}$} \\
\hline Flow rate & \multicolumn{4}{|c|}{$1.0 \mathrm{ml} / \mathrm{min}$} \\
\hline Injection volume & \multicolumn{4}{|c|}{$20 \mu \mathrm{l}$} \\
\hline \multirow{8}{*}{$\begin{array}{l}\text { Mobile phase conditions for } \\
\text { HPLC gradient-elution }\end{array}$} & Program order & Time (min) & $2 \% \mathrm{AA}^{1)}$ in water $(\%)$ & $0.5 \% \mathrm{AA}^{1)}$ in $50 \% \mathrm{ACN}^{2)}(\%)$ \\
\hline & 1 & 0 & 100 & 0 \\
\hline & 2 & 10 & 100 & 0 \\
\hline & 3 & 150 & 50 & 50 \\
\hline & 4 & 200 & 30 & 70 \\
\hline & 5 & 210 & 30 & 70 \\
\hline & 6 & 215 & 100 & 0 \\
\hline & 7 & 220 & 100 & 0 \\
\hline
\end{tabular}

${ }^{1)} \mathrm{AA}$ : Acetic acid, ${ }^{2)} \mathrm{ACN}$ : Acetonitrile

in the same manner as the minimum inhibitory concentration, except that $10 \mu \mathrm{l}$ each of two different samples are mixed [17]. That is, in the checkerboard test, two samples in different concentration are added to each well. Sample A was diluted 2-fold, and then sample B diluted 2-fold was added. The resulting mixture was incubated with one of the six microorganisms. After incubation, the ratio between Sample A and Sample B at which the growth of the microorganism was not observed visually was determined. The fractional inhibition concentration (FIC) and FIC index were then calculated.

$$
\begin{aligned}
& \text { FIC index }=F I C_{A}+F I C_{B} \\
& =\left(\frac{M I C A_{\text {combination } A B}}{M I C_{\text {agent } A}}\right)+\left(\frac{M I C B_{\text {combination } A B}}{M I C_{\text {agent } B}}\right)
\end{aligned}
$$

If the FIC index $\leq 0.5$, the effects are synergistic; if $0.5<$ FIC index $\leq 1$, the effects are additive; if $1<$ FIC index $\leq 4$ there is no difference between individual and combined effects; and if FIC index $>4$, the effects are antagonistic [17].

Kill-time analysis. Kill-time analysis is a method used to measure the change in the number of bacterial colonies in the culture medium upon the addition of the sample over time [17]. The experiment was conducted using a specific sample concentration selected based on the result of the checkerboard test. For the analysis, $0.5 \mathrm{ml}$ of the sample was added to $4.5 \mathrm{ml}$ of the bacterial suspension $\left(10^{5} \mathrm{CFU} / \mathrm{ml}\right)$. This was then incubated at 3-h intervals for 18 hours. Between each interval, the change in the number of bacterial colonies was determined.

\section{Componential Analysis of Each Extract}

The ethyl acetate fraction from each of the two extracts was dissolved in $100 \%$ ethanol and filtered using a syringe filter

\begin{tabular}{|c|c|c|c|c|}
\hline & \multicolumn{4}{|c|}{ Condition of HPLC analysis } \\
\hline Column & \multicolumn{4}{|c|}{ Shim-pack VP-ODS C18 Column (L : $250 \mathrm{~mm}, \mathrm{LD}: 4.6 \mathrm{~mm}, 5 \mu \mathrm{m})$} \\
\hline Detector & \multicolumn{4}{|c|}{ UVD 170s DIONEX } \\
\hline Detection wavelength & \multicolumn{4}{|c|}{$254-400 \mathrm{~nm}$} \\
\hline Flow rate & \multicolumn{4}{|c|}{$1.0 \mathrm{ml} / \mathrm{min}$} \\
\hline Injection volume & \multicolumn{4}{|c|}{$20 \mu \mathrm{l}$} \\
\hline \multirow{6}{*}{$\begin{array}{l}\text { Mobile phase conditions for } \\
\text { HPLC gradient-elution }\end{array}$} & Program order & Time (min) & $\mathrm{DW}^{1)}(\%)$ & $100 \% \mathrm{ACN}^{2)}(\%)$ \\
\hline & 1 & 0 & 75 & 25 \\
\hline & 2 & 40 & 50 & 50 \\
\hline & 3 & 60 & 5 & 95 \\
\hline & 4 & 70 & 5 & 95 \\
\hline & 5 & 75 & 95 & 5 \\
\hline
\end{tabular}

Table 2. HPLC conditions for separation of EtOAc fraction from M. obovata.

\footnotetext{
${ }^{1)} \mathrm{DW}$ : Distilled Water, ${ }^{2)} \mathrm{ACN}$ : Acetonitrile
} 
(Millipore, USA, $0.45 \mu \mathrm{m}$ ). The filtered extract solution was then subjected to nonpolar HPLC (C18) analysis. HPLC analysis of the L. japonica extract was performed through gradient elution using a $2 \%$ aqueous solution of acetic acid and a $50 \%$ aqueous solution of acetonitrile containing $0.5 \%$ acetic acid. HPLC separation conditions are shown in Table 1. HPLC analysis of M. obovata was performed through gradient elution using distilled water and $100 \%$ acetonitrile. HPLC separation conditions are shown in Table 2.

\section{Statistical Analysis}

All experiments were conducted in triplicate, averaged and presented followed by the standard deviation.

\section{Results and Discussion}

\section{Extraction Yields of L. japonica and M. obovata}

The yields of the $50 \%$ ethanol extract and the ethyl acetate fraction from L. japonica were $4.85 \%$ and $0.41 \%$, respectively. The yields of the $70 \%$ ethanol extract and the ethyl acetate fraction from M. obovata were $14.52 \%$ and $4.47 \%$, respectively (Table 3 ).

\section{Antimicrobial Activity of L. japonica and M. obovata Extracts}

The antimicrobial activities of L. japonica and M. obovata extracts were evaluated against six strains. MIC and MBC were used as the parameters. The results are shown in Table 4 .

The 50\% ethanol extract from $L$. japonica exhibited antibacterial activity only against $S$. aureus and P. aeruginosa. Its antimicrobial activity was not as high as that of
Table 3. Yields of L. japonica and M. obovata extractions.

\begin{tabular}{clc}
\hline & \multicolumn{1}{c}{ Solvent } & Yield $(\%, \mathrm{w} / \mathrm{w})^{*}$ \\
\hline Lonicera japonica & $50 \%$ EtOH extract & 4.85 \\
& EtOAc fraction & 0.41 \\
Magnolia obovata & $70 \%$ EtOH extract & 14.52 \\
& EtOAc fraction & 4.47 \\
\hline
\end{tabular}

${ }^{*}$ Yield $(\%, w / w)=($ weight of dried extract $/$ weight of dried raw material $) \times 100$

methylparaben, which was used as a control. On the other hand, the ethyl acetate fraction from L. japonica exhibited antimicrobial activity against all strains. In particular, the activity of the fraction against $S$. aureus and P. aeruginosa was higher than that of the control. However, antimicrobial activity of the fraction against $C$. albicans was similar to that of the control.

The $70 \%$ ethanol extract and ethyl acetate fraction from M. obovata exhibited antimicrobial activity against the six strains. In particular, the antimicrobial activity of the extract against $S$. aureus, B. subtilis, P. aeruginosa, and C. albicans was similar to or higher than that of the control. Against all strains except B. subtilis and E. coli, the antimicrobial activities of the ethyl acetate fraction was found to be about 2 to 4 times higher than those of the $70 \%$ ethanol extract.

\section{Synergistic Antimicrobial Effects of L. japonica and M. obovata}

The synergistic antimicrobial effect of the two extracts was evaluated using the ethyl acetate fractions from L. japonica and M. obovata since these fractions showed high

Table 4. Minimum Inhibitory Concentration (MIC, ug/ml) and Mininum Bactericidal Concentration (MBC) of L. japonica and M. obovata extracts and fractions.

\begin{tabular}{|c|c|c|c|c|c|c|}
\hline \multirow{3}{*}{ Strains } & \multicolumn{6}{|c|}{$\mathrm{MIC}(\mathrm{MBC})(\mathrm{ug} / \mathrm{ml})$} \\
\hline & \multicolumn{2}{|c|}{ Gram positive bacteria } & \multicolumn{2}{|c|}{ Gram negative bacteria } & \multirow{2}{*}{$\begin{array}{c}\text { Yeast } \\
\text { C. albicans }\end{array}$} & \multirow{2}{*}{$\begin{array}{c}\text { Mold } \\
\text { A. brasiliensis }\end{array}$} \\
\hline & S. aureus & B. subtilis & E. coli & P. aeruginosa & & \\
\hline Lonicera japonica & 5000 & - & - & 5000 & - & - \\
\hline $50 \%$ EtOH extract & $(10000)$ & $(-)$ & $(-)$ & $(-)$ & $(-)$ & $(-)$ \\
\hline Lonicera japonica & 78 & 10000 & 5000 & 312 & 1250 & 10000 \\
\hline Magnolia obovata & 78 & 2500 & 2500 & 1250 & 1250 & 10000 \\
\hline $70 \%$ EtOH extract & $(156)$ & $(2500)$ & $(5000)$ & $(1250)$ & $(5000)$ & $(-)$ \\
\hline Magnolia obovata & 39 & 2500 & 2500 & 625 & 625 & 2500 \\
\hline EtOAc fraction & (78) & $(5000)$ & $(2500)$ & $(625)$ & $(625)$ & $(-)$ \\
\hline \multirow[t]{2}{*}{ Methyl paraben } & 2500 & 2500 & 1250 & 1250 & 1250 & 625 \\
\hline & $(5000)$ & & $(5000)$ & (1250) & (5000) & (5000) \\
\hline
\end{tabular}

Methylparaben used as a control. - no inhibition at 10,000 ug $/ \mathrm{ml}$. 

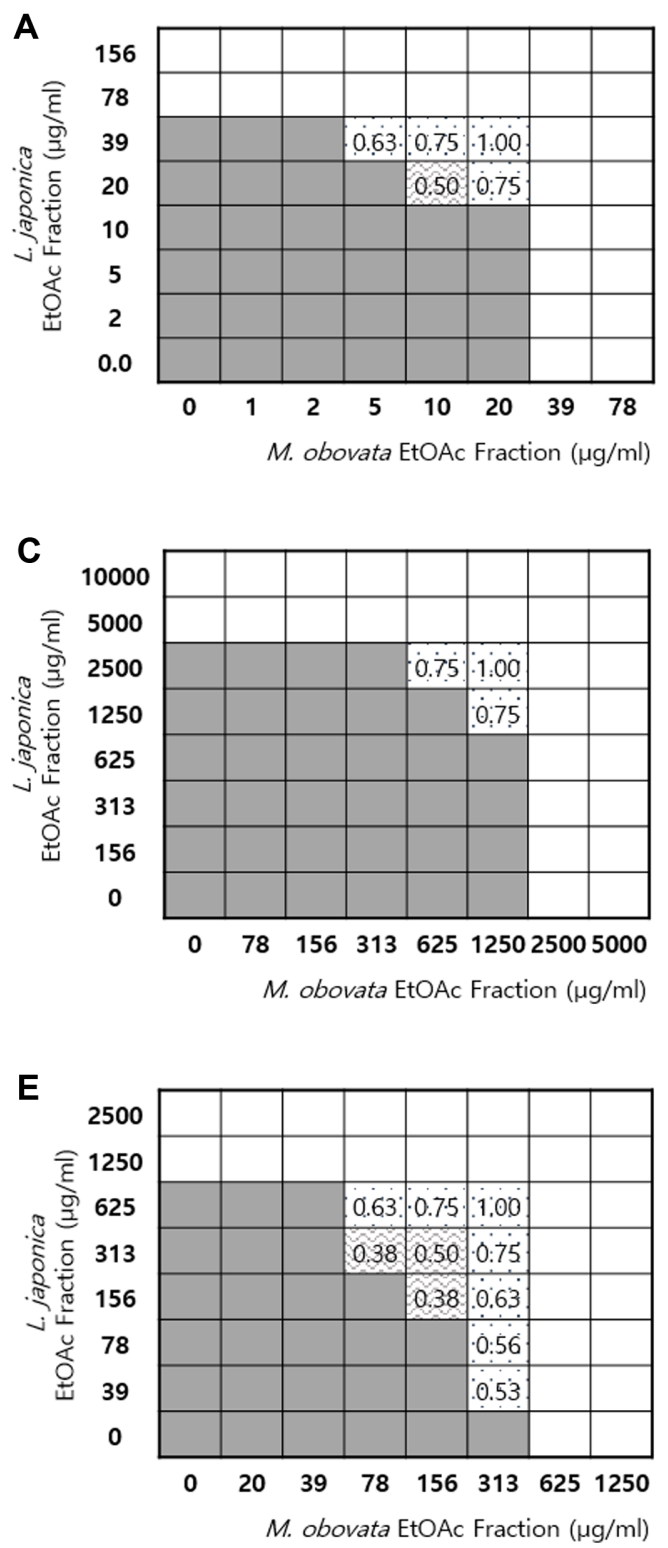
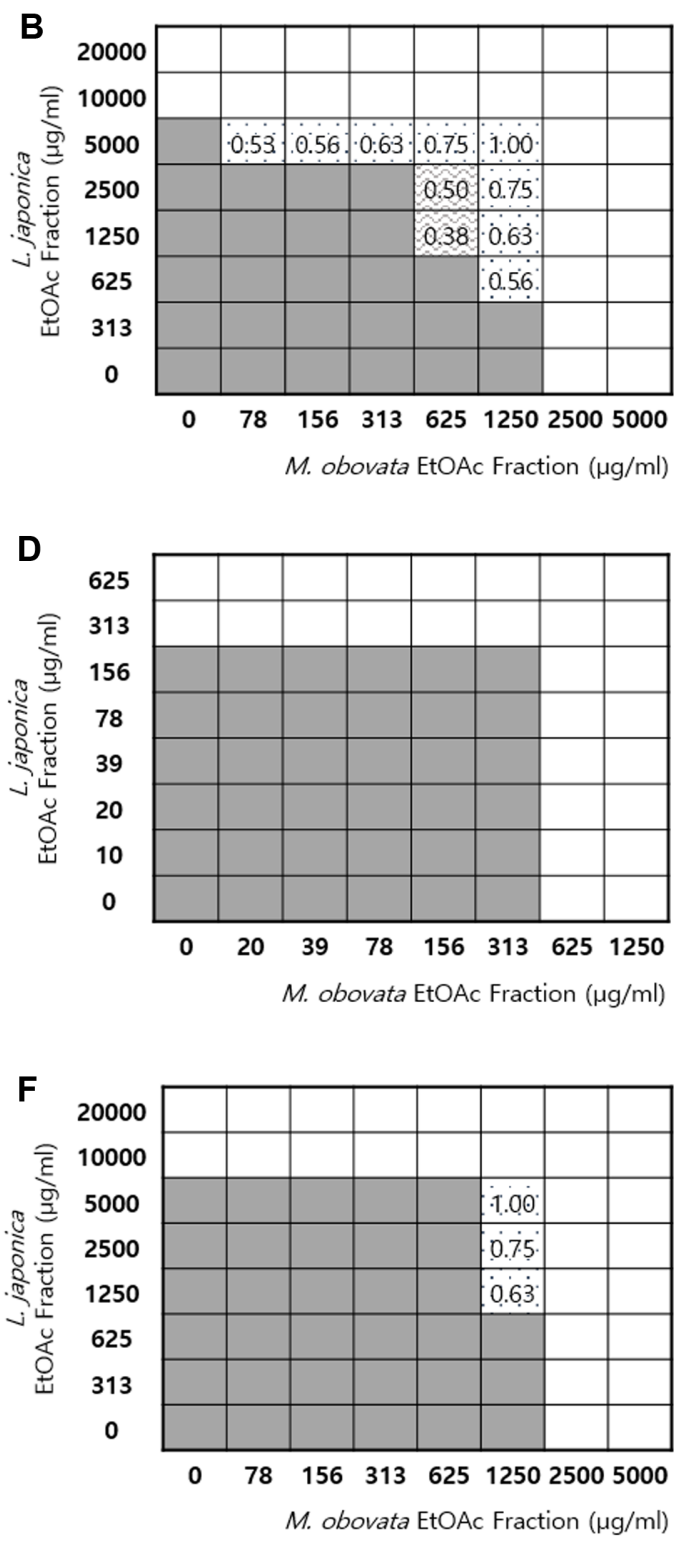

Fig. 1. Checkerboard test showing the synergistic antimicrobial effects of L. japonica and M. obovata fractions against six microorganisms.

(A) S. aureus, (B) B. subtilis, (C) E. coli, (D) P. aeruginosa, (E) C. albicans, (F) A. brasiliensis. Colored wells indicate microbial growth and white wells indicate no microbial growth. The number in the well is the FIC index. Wave patterns indicate the synergistic effect (FIC index $\leq 0.5$ ) and dotted patterns mean an addition effect $(0.5<$ FIC index $\leq 1)$.

antimicrobial activities against all six strains. The synergistic effect was confirmed through the checkerboard test and the FIC index, which were also used to determine whether there is an additive effect or an indifferent effect upon combined use of the extracts. Additionally, kill-time analysis was conducted using the concentrations and combination at which a synergistic effect against $B$. subtilis was observed.

Checkerboard test. The checkerboard test was used to confirm the synergistic effect of the ethyl acetate fractions from the two extracts, which showed antimicrobial activity against all six strains. The results are shown in Fig. 1. A synergistic effect was observed against $S$. aureus, B. subtilis, and C. albicans.

A synergistic antimicrobial effect was observed against S. aureus; FIC was calculated to be 0.5 at $20 \mathrm{ppm}$ L. japonica and $10 \mathrm{ppm}$ M. obovata. Additive effects were also observed 
at four ratios of the two extracts. Against B. subtilis, the FIC value was 0.5 at $2,500 \mathrm{ppm} L$. japonica and $625 \mathrm{ppm}$ M. obovata. The results indicate two ratios with synergistic effects and eight with additive effects. Against C. albicans, an FIC value of 0.5 was determined at 313 ppm L. japonica and $156 \mathrm{ppm} \mathrm{M}$. obovata, and the numbers of ratios showing a synergistic effect and an additive effect were 3 and 7, respectively. No synergistic effect was observed against E. coli and A. brasiliensis, but additive effects were confirmed. Against $P$. aeruginosa, no synergistic nor additive effects were observed. It appears that the combination of the two extracts has weaker antimicrobial activity than each extract only against $P$. aeruginosa. Therefore, we confirmed that a mixture of L. japonica and M. obovata ethyl acetate fractions exhibits antibacterial synergy against S. aureus, B. subtilis, and C. albicans.

Kill-time analysis. In the previous experiment, we confirmed that the combination of L. japonica and M. obovata ethyl acetate fractions exhibits antimicrobial synergy against $S$. aureus, B. subtilis, and C. albicans. Kill-time analysis was conducted against $B$. subtilis since the synergistic and additive effects were highest against this strain. The control group was treated with DMSO only. The concentration of the ethyl acetate fraction from L. japonica was 2,500 ppm while the concentration of the ethyl acetate fraction from $M$. obovata was $625 \mathrm{ppm}$. The combination of L. japonica and M. obovata extracts was applied to the microbial strain, and the viable cell count was determined at different time points. The results are shown in Fig. 2.

We found that upon treatment with the L. japonica

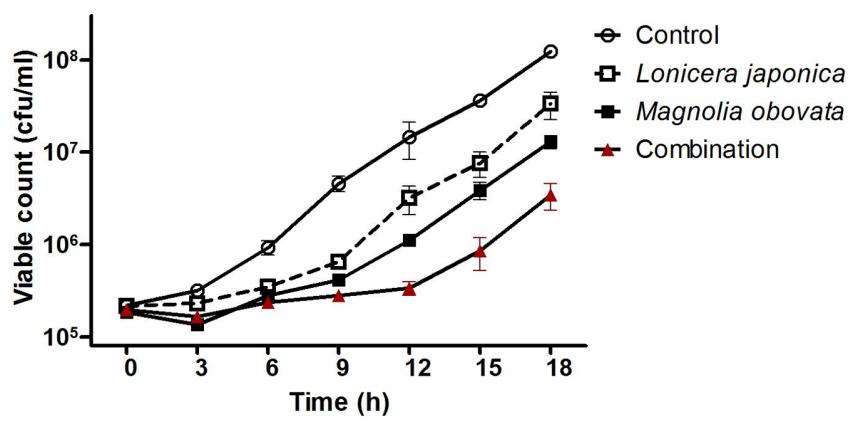

Fig. 2. The synergistic antimicrobial effects of L. japonica and M. obovata fractions against $B$. subtilis by kill-time analysis. Control $(\bigcirc)$ was treated with DMSO only and the concentration of the ethyl acetate fraction from L. japonica $(\square)$ and M. obovate ( $\square$ ) was 2,500 ppm and 625 ppm, respectively. Combination ( $\mathbf{\Delta})$ indicates a mixture of L. japonica and M. obovata fractions. The experiments were conducted at 3-h intervals for $18 \mathrm{~h}$ and in triplicate. Data are presented as the mean \pm SD. extract, the bacterial population increased gradually over time. Addition of the M. obovata extract also resulted in a gradual increase in bacterial population over time, but at a slightly lower rate than when $L$. japonica was added. Treatment with either the L. japonica or the M. obovata extract resulted in lower bacterial counts than the control, suggesting that the extracts had an antibacterial effect. When the L. japonica and M. obovata extracts were added in combination, the resulting bacterial count was about 10 times lower than when only each of the extracts was applied. This confirms that combining the two extracts enhances their antibacterial effects. Thus, the synergistic antimicrobial effects of L. japonica and $M$. obovata against B. subtilis was reconfirmed through kill-time analysis.
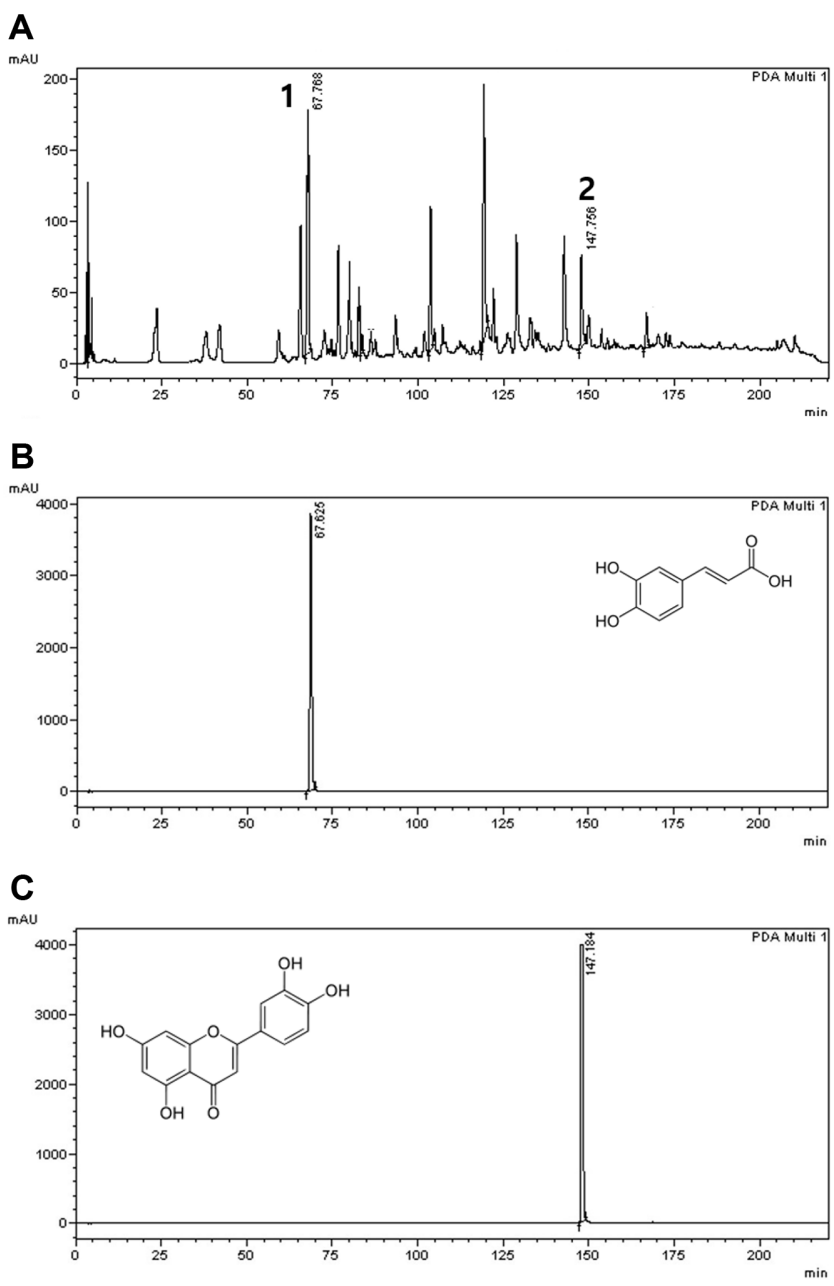

Fig. 3. The HPLC chromatogram of ethyl acetate fraction of L. japonica and the components in detection wavelength range from 254 to $400 \mathrm{~nm}$.

(A) Ethyl acetate fraction, caffeic acid; 1, luteolin; 2. (B) Caffeic acid. (C) Luteolin. 
A

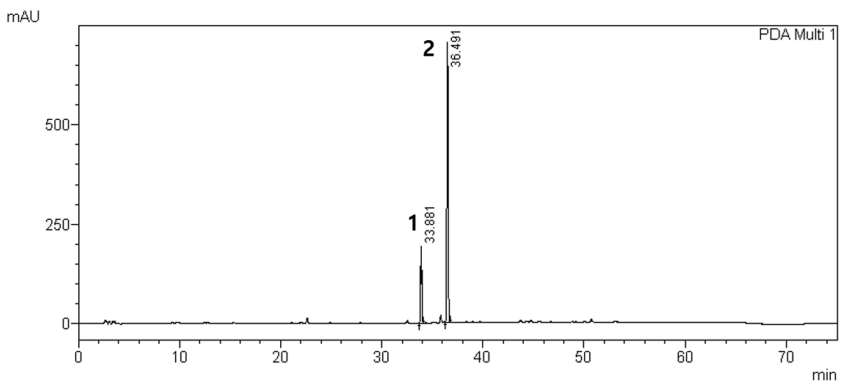

B

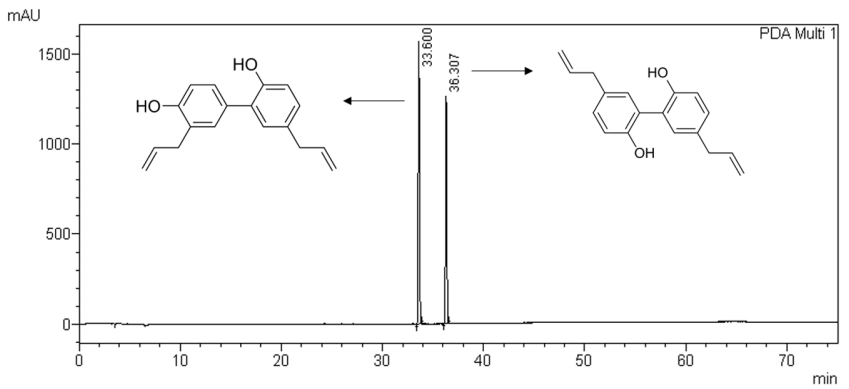

Fig. 4. The HPLC chromatogram of ethyl acetate fraction of M. obovate and the components in detection wavelength range from 254 to $400 \mathrm{~nm}$.

(A) Ethyl acetate fraction, honokiol; 1, magnolol; 2. (B) Magnolol and honokiol (standard).

\section{Componential Analysis of L. japonica and M. obovata}

Since we have confirmed that the extracts have antimicrobial activities against the six strains, we used HPLC to determine the effective components of each extract. The results are shown in Figs. 3 and 4.

HPLC analysis of the L. japonica ethyl acetate fraction revealed two components, caffeic acid and luteolin. In Fig. 3, a peak for caffeic acid in the L. japonica ethyl acetate fraction was confirmed at $67.768 \mathrm{~min}$ and a peak for luteolin at $147.756 \mathrm{~min}$. Caffeic acid, a phenolic compound, is mainly found in coffee beans, fruits, and herbs such as thyme, and is known to have antioxidant and anticancer properties [18, 19]. Luteolin, which has a flavone structure, is usually found in peanut shells, parsley, and celery, and is known to have antioxidant, anti-inflammatory, and cytoprotective properties [20-23].

Analysis of the M. obovata ethyl acetate fraction revealed two clear peaks that were identified as magnolol and honokiol. In Fig. 4, a peak for honokiol in the M. obovata ethyl acetate fraction was confirmed at $33.881 \mathrm{~min}$ and a peak for magnolol at $36.491 \mathrm{~min}$. Magnolol and honokiol
A

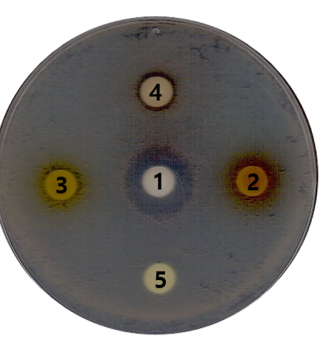

\begin{tabular}{c|c|c}
\hline No. & \multicolumn{1}{|c}{ Sample } & $\begin{array}{c}\text { Clear zone } \\
(\mathbf{m m})\end{array}$ \\
\hline 1 & Methyl paraben & 18 \\
\hline 2 & $\begin{array}{l}\text { L. japonica } \\
50 \% \text { EtOH extract }\end{array}$ & 8 \\
\hline 3 & $\begin{array}{l}\text { L. japonica } \\
\text { EtOAc fraction }\end{array}$ & 9 \\
\hline 4 & Caffeic acid & 10 \\
\hline 5 & Luteolin & - \\
\hline
\end{tabular}

B

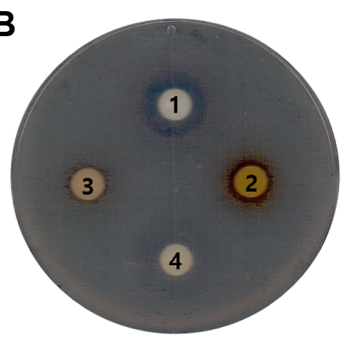

\begin{tabular}{c|c|c}
\hline No. & \multicolumn{1}{|c}{ Sample } & $\begin{array}{c}\text { Clear zone } \\
(\mathbf{m m})\end{array}$ \\
\hline 1 & Methyl paraben & 16 \\
\hline 2 & $\begin{array}{l}\text { M. obovata } \\
70 \% \text { EtOH extract }\end{array}$ & 11 \\
\hline 3 & $\begin{array}{l}\text { M. obovata } \\
\text { EtOAc fraction }\end{array}$ & 10 \\
\hline 4 & Magnolol,Honokiol & 8 \\
\hline
\end{tabular}

Fig. 5. Antimicrobial activities of L. japonica, M. obovata extracts/fractions and the components against $P$. aerusinosa by disc diffusion assay.

(A) Methylparaben (as a control); 1, L. japonica 50\% EtOH extract; 2, L. japonica EtOAc fraction; 3, caffeic acid; 4, luteolin; 5. (B) Methylparaben (as a control); 1, M. obovata $70 \% \mathrm{EtOH}$ extract; 2, M. obovata EtOAc fraction; 3, magnolol and honokiol; 4 .

are classified as lignans and are compounds that exist as isomers. These are found mainly in the bark of magnolia trees and are known to possess antioxidant and antibacterial properties [24, 25]. HPLC analysis confirmed the presence of caffeic acid and luteolin in L. japonica and magnolol and honokiol in M. obovata.

\section{Antimicrobial Effects of the Components of L. japonica and M. obovata Extracts}

The antimicrobial activity of each component of each extract was evaluated, and the relationship between the antimicrobial activity of the extract and that of each component was determined. The antimicrobial activity was evaluated through a disc diffusion assay and the minimum inhibition concentration.

Disc diffusion assay. To evaluate the antimicrobial activity of each component of the L. japonica and M. obovata extracts, we performed disc diffusion assay. Antimicrobial activity was indicated by the presence of a clear zone around the disc containing the sample. For all samples except luteolin, $5 \mathrm{mg}$ was added onto each disc, while for luteolin, only $0.05 \mathrm{mg}$ was added.

As shown in Fig. 5, the results were most effective against $P$. aeruginosa, with the clear zones around the discs containing the $50 \%$ ethanol extract and the ethyl acetate 
Table 5. Minimum Inhibitory Concentration (MIC, $\mathrm{ug} / \mathrm{ml}$ ) of the components of L. japonica and M. obovata extracts.

\begin{tabular}{|c|c|c|c|c|c|c|}
\hline \multirow{3}{*}{ Strains } & \multicolumn{6}{|c|}{ MIC (ug/ml) } \\
\hline & \multicolumn{2}{|c|}{ Gram positive bacteria } & \multicolumn{2}{|c|}{ Gram negative bacteria } & \multirow{2}{*}{$\begin{array}{c}\text { Yeast } \\
\text { C. albicans }\end{array}$} & \multirow{2}{*}{$\frac{\text { Mold }}{\text { A. brasiliensis }}$} \\
\hline & S. aureus & B. subtilis & E. coli & P. aeruginosa & & \\
\hline Methyl paraben & 1250 & 1250 & 1250 & 1250 & 1250 & 625 \\
\hline Caffeic acid & 312 & 5000 & 5000 & 2500 & 5000 & $>10000$ \\
\hline Luteolin & 25 & 200 & 200 & 50 & 200 & 200 \\
\hline Magnolol, Honokiol & 31.2 & 10000 & 10000 & 1250 & 5000 & 39 \\
\hline
\end{tabular}

Methylparaben used as a control.

fraction from L. japonica measuring $8 \mathrm{~mm}$ and $9 \mathrm{~mm}$ in diameter, respectively. These activities were lower than that of the control, methylparaben $(18 \mathrm{~mm})$. Caffeic acid, one of the components of the L. japonica extract, produced a 10-mm clear zone, while luteolin did not inhibit bacterial growth. Similarly, the $70 \%$ extract and the ethyl acetate fraction from $M$. obovata showed inhibitory activities, as indicated by the clear zones $(11 \mathrm{~mm}$ and $10 \mathrm{~mm}$, respectively) around the corresponding discs, which were lower than that of the control, methylparaben $(16 \mathrm{~mm})$. Magnolol and honokiol, which are the main components of the extract, did not produce clear zones.

Minimum inhibitory concentration (MIC). To accurately evaluate the antimicrobial activity of each component of the L. japonica and M. obovata extracts, the minimum inhibitory concentration was determined. The results are shown in Table 5.

Caffeic acid showed high antimicrobial activity against S. aureus and $P$. aeruginosa, and low antimicrobial activity against B. subtilis, E. coli, and C. albicans. No antimicrobial activity against $A$. brasiliensis was detected even at high concentrations of the components. On the other hand, luteolin exhibited antimicrobial activity against all strains at low concentrations and showed excellent antimicrobial activity especially against $S$. aureus and $P$. aeruginosa. This suggests that the no inhibition by luteolin was detected in the disc diffusion assay because the concentration of the compound used was too low. As shown in Table 4, the 50\% ethanol extract from $L$. japonica exhibited antimicrobial activity against $S$. aureus and $P$. aeruginosa. This can be explained by the activity of caffeic acid, which has relatively high polarity, since the extract and this component had antibacterial activities against the same strains. On the other hand, the antimicrobial activities of the ethyl acetate fraction from L. japonica were observed against six strains, which is expected as a result of the influence of luteolin, a nonpolar component.

Magnolol and honokiol showed antimicrobial activity against all strains, especially $S$. aureus, $P$. aeruginosa, and A. brasiliensis. These results suggest that the antimicrobial effects of the M. obovata extract can be attributed to the presence of magnolol and honokiol. In addition, the antimicrobial effects of the extract may be a result of the interaction between magnolol, honokiol, and other ingredients since the antimicrobial effects of the extracts are superior to those of each component.

In this study, we evaluated the antimicrobial activities of L. japonica and M. obovata extracts in order to examine their potential as natural preservatives. We found that the 50\% ethanol extract from L. japonica had antimicrobial activities against $S$. aureus and $P$. aeruginosa, and the ethyl acetate fraction had antimicrobial activities against all six strains tested. On the other hand, the $70 \%$ ethanol extract and ethyl acetate fraction from M. obovata showed antimicrobial activities against all six strains, with particularly high activities against $S$. aureus, $P$. aeruginosa, and C. albicans.

We also evaluated the synergistic antimicrobial activity of the ethyl acetate fractions from L. japonica and M. obovata, both of which showed antimicrobial activity against all six strains. We showed that the two fractions acted in synergy against S. aureus, B. subtilis, and C. albicans. This was reconfirmed through kill-time analysis against $B$. subtilis.

To determine the extract components that have antimicrobial activity, we performed HPLC analysis and detected the presence of caffeic acid and luteolin in the L. japonica extract and magnolol and honokiol in the M. obovata extract. The results of the disc diffusion assay and the minimum inhibitory concentration indicate that the antimicrobial activity of L. japonica is influenced by caffeic acid and luteolin. On the other hand, the antimicrobial activity of M. obovata was a result of the interaction among magnolol, honokiol, and other compounds. Moreover, further research, such as on the mechanisms underlying the antimicrobial activities of the two extracts and on a challenge test (preservative effectiveness test) of products containing the extracts, should be conducted. Thus, this 
study suggests that a combination of the L. japonica and M. obovata extracts may be applicable as a plant-derived natural preservative.

\section{Conflict of Interest}

The authors have no financial conflicts of interest to declare.

\section{References}

1. Park J, Choi M. 2011. Antimicrobial activity and antiinflammation effect to the human skin pathogens by the Rumex crispus L. root extracts. Kor. J. Aesthet Cosmetol. 9: 9-16.

2. Textbook compilation committee of Korean Dermatological Association. 2002. Textbook of dermatology, pp. 1-3. 4th Ed. The Ryo Moon Gak.P.Co, Seoul.

3. Kerscher M, Dubertret L. 2007. Cosmetic dermatology and skin care. Eur. J. Dermatol. 17: 180-182.

4. Jang Y, Lee J. 2014. An investigation into antioxidant effects of Glycyrrhiza uralensis Fisch, Forsythia suspensa Vahl, Coptis chinensis Franch and antibacterial activities against cutaneous microorganisms. J. Kor. Soc. Cosm. 20: 247-252.

5. Smart R, Spooner D. 1972. Microbiological spoilage in pharmaceuticals and cosmetics. J. Soc. Cosmet. Chem. 23: 721-737.

6. Ku J-E, Han H-S, Song J-H. 2013. The recent trend of the natural preservative used in cosmetics. Kor. J. Aesthetics Cosmetol. 11: 835-844.

7. Chae K-Y, Kim J-E, Park S-N. 2012. Antibacterial activity of Hippophae rhamnoides Leaf extract and the stability of a cream with the extract. Microbiol. Biotechnol. Lett. 40: 43-49.

8. Lee J-Y, Lee J-N, Lee G-T, Lee K-K. 2012. Development of antimicrobial plant extracts and its application to cosmetics. J. Soc. Cosmet. Sci. Kor. 38: 171-179.

9. Xiong J, Li S, Wang W, Hong Y, Tang K, Luo Q. 2013. Screening and identification of the antibacterial bioactive compounds from Lonicera japonica Thunb. leaves. Food Chem. 138: 327-333.

10. Yoo HJ, Kang HJ, Song YS, Park EH, Lim CJ. 2008. Antiangiogenic, antinociceptive and anti-inflammatory activities of Lonicera japonica extract. J. Pharm. Pharmacol. 60: 779-786.

11. Han JM, Kim MH, Choi YY, Lee H, Hong J, Yang WM. 2015. Effects of Lonicera japonica Thunb. on type 2 diabetes via PPAR- $\gamma$ activation in rats. Phytother. Res. 29: 1616-1621.

12. GS Hwang, DH Lee, HJ Lee. 2014. Antioxidant activity and components of Lonicera japonica Thunb. Available from http://
www.dbpia.co.kr/Journal/ArticleDetail/NODE02513133\#. The Plant Resources Society of Korea. 173.

13. Haraguchi H, Ishikawa H, Shirataki N, Fukuda A. 1997. Antiperoxidative activity of neolignans from Magnolia obovata. J. Pharm. Pharmacol. 49: 209-212.

14. Chan LW, Cheah EL, Saw CL, Weng W, Heng PW. 2008. Antimicrobial and antioxidant activities of Cortex Magnoliae Officinalis and some other medicinal plants commonly used in South-East Asia. Chin. Med. 3: 15.

15. Oh JH, La Kang L, Ban JO, Kim YH, Kim KH, Han SB, et al. 2009. Anti-inflammatory effect of 4-O-methylhonokiol, a novel compound isolated from Magnolia officinalis through inhibition of NF-кB. Chem. Biol. Interact. 180: 506-514.

16. Nakazawa T, Yasuda T, Ohsawa K. 2003. Metabolites of orally administered Magnolia officinalis extract in rats and man and its antidepressant-like effects in mice. J. Pharm. Pharmacol. 55: 1583-1591.

17. Sopirala MM, Mangino JE, Gebreyes WA, Biller B, Bannerman T, Balada-Llasat J-M, et al. 2010. Synergy testing by Etest, microdilution checkerboard, and time-kill methods for pan-drug-resistant Acinetobacter baumannii. Antimicrob. Agents Chemother. 54: 4678-4683.

18. Gülçin İ. 2006. Antioxidant activity of caffeic acid (3, 4dihydroxycinnamic acid). Toxicology 217: 213-220.

19. Prasad NR, Karthikeyan A, Karthikeyan S, Reddy BV. 2011. Inhibitory effect of caffeic acid on cancer cell proliferation by oxidative mechanism in human HT-1080 fibrosarcoma cell line. Mol. Cell Biochem. 349: 11-19.

20. Sato Y, Itagaki S, Kurokawa T, Ogura J, Kobayashi M, Hirano $\mathrm{T}$, et al. 2011. In vitro and in vivo antioxidant properties of chlorogenic acid and caffeic acid. Int. J. Pharm. 403: 136-138.

21. Pietta P-G. 2000. Flavonoids as antioxidants. J. Nat. Prod. 63: 1035-1042.

22. Torel J, Cillard J, Cillard P. 1986. Antioxidant activity of flavonoids and reactivity with peroxy radical. Phytochemistry 25: 383-385.

23. Seibert H, Maser E, Schweda K, Seibert S, Gülden M. 2011. Cytoprotective activity against peroxide-induced oxidative damage and cytotoxicity of flavonoids in C6 rat glioma cells. Food Chem. Toxicol. 49: 2398-2407.

24. Ogata M, Hoshi M, Shimotohno K, Urano S, Endo T. 1997. Antioxidant activity of magnolol, honokiol, and related phenolic compounds. J. Am. Oil Chem. Soc. 74: 557-562.

25. Bang KH, Kim YK, Min BS, Na MK, Rhee YH, Lee JP, et al. 2000. Antifungal activity of magnolol and honokiol. Arch. Pharm. Res. 23: 46-49. 